\title{
Superação do Vitalismo e o Imparável Desenvolvimento da Síntese OrgânICA
}

\author{
Fátima Paixão ${ }^{1, *}$ e Mariette M. Pereira ${ }^{2}$
}

\begin{abstract}
A síntese orgânica representou um marco capital na História da Química, conduzindo ao fim da filosofia vitalista que considerava que as substâncias constitutivas dos animais e das plantas eram de natureza diferente dos corpos minerais, não obedecendo às mesmas leis, nem podendo ser feitas em laboratório. Quase dois séculos volvidos, a filosofia emergente é, agora, a de uma síntese verde, ambientalmente mais sustentável.
\end{abstract}

Se o ano de 1789, com a publicação do Tratado Elementar de Química, de Lavoisier, marca, verdadeiramente, o nascimento da Química moderna, o desenvolvimento desta ciência, a partir do século XIX, foi assombroso para a humanidade. No início desse século, a diferença entre Química Mineral e Química Orgânica, que dava à segunda o domínio das substâncias cuja origem era um ser vivo, animal ou planta, era codificada numa filosofia vitalista que atribuía exclusivamente à vida, através de um criador, a possibilidade da existência de tais materiais que não poderiam ser feitos em laboratório $[1,2]$.

Berthollet e, ao mesmo tempo, Lavoisier, mostraram que as substâncias orgânicas, afinal, contém elementos conhecidos como o carbono, o hidrogénio, o oxigénio e, por vezes, o azoto ou mesmo outros elementos. Cerca de 1811, Gay-Lussac e Thénard realizaram algumas análises quantitativas em corpos orgânicos e, em 1823, Chevreul isolava e identificava completamente a composição dos ácidos gordos de origem animal e da glicerina [1]. O resultado prático imediato foi a substituição da candeia de sebo pela vela de estearina. Seguiramse, entre outras, as identificações da morfina (extraída do ópio e com forte acção analgésica), da quinina (extraída da chinchona e usada nas águas

\footnotetext{
"Escola Superior de Educação, Instituto Politécnico de Castelo Branco;

tónicas), da estricnina (extraída da noz vómica e conhecido veneno para ratos)... Os métodos de análise orgânica foram desenvolvidos depois de 1830, por Liebig. Tratava-se apenas, nestes processos, de decompor as substâncias e de reconhecer os seus constituintes; a reconstituição, ou seja, a síntese, permanecia impraticada e, segundo as ideias vitalistas, impraticável. Assim, se os compostos orgânicos não podiam ser feitos em laboratório e precisavam de uma força vital, seria legítima a dúvida relativa a que leis obedeceriam tais corpos. A resposta viria a estar, afinal, no percurso da Química Orgânica, no seu desenvolvimento ao longo do século XIX.

Um passo largo no caminho do desenvolvimento da Química Orgânica foi dado por Berzelius (1779-1848), químico sueco, experimentalista notável que levou a cabo inúmeras análises e descobriu o selénio e o tório e isolou o cálcio, o silício, o vanádio e o zircónio. Em 1826, publicou a primeira tabela de pesos atómicos com quarenta e dois elementos e de uma extraordinária precisão. A ele se deve a utilização das representações dos símbolos pela primeira letra ou pelas duas primeiras do nome em latim da substância simples e a introdução das noções de isomeria e de polimeria. Simultaneamente ao estudo, em 1823 , em Paris, por Liebig, do fulminato de prata, o alemão Wohler, no laboratório de Berzelius, em Estocolmo, ao analisar o cianeto de prata, encontrou a mesma fórmula química. Berzelius, alertado, dispôs-se a repetir exaustivamente as análises até que cedeu à ideia de que corpos diferentes podiam ter a mesma composição química, ou seja, serem isómeros entre si. Em 1827, este químico explicava as diferenças das propriedades dos dois compostos como resultado de duas diferentes forças vitais. E, sempre guiado pelo seu paradigma, descobriu, ainda, a catálise, uma combinação na qual um certo corpo saía das reacções tal como entrara.

O maior inimigo de Berzelius foi o francês Dumas (1800-1884), a quem se chama, com grande frequência, o fundador da Química Orgânica, e com quem aquele se viria a cruzar nas polémicas das interpretações teóricas que opunham o vitalismo e o atomismo naturalista. Dumas tornouse ilustre pelos trabalhos sobre o álcool metílico, o anil, o álcool amílico, os amidos, os adubos, ou seja, no domínio então privilegiado da Química Orgânica.

E se Dumas foi o pai da Química Orgânica, estava reservado a Wohler a execução da primeira síntese orgânica que teve lugar no mundo. Em 1824, este químico sintetizou o ácido oxálico a partir de substâncias minerais e, no ano de 1828 , seria sintetizada a ureia sem necessidade de rins ou, sequer, de qualquer ser vivo. Apesar disto, Berzelius continuava, ainda, firme na defesa do vitalismo e considerava as novas teorias emergentes como perigosas extrapolações filosóficas. Na sua ideia, mesmo que 
com o tempo se conseguisse produzir, com corpos inorgânicos, várias substâncias de composição análoga à dos produtos orgânicos, esta imitação incompleta seria demasiado restrita para que se pudesse esperar produzir corpos orgânicos, tal como se conseguia, na maior parte dos casos, confirmar a análise dos corpos inorgânicos fazendo a sua síntese. Outros, como Gerhardt, embora considerassem as sínteses realizadas por Wohler devidas ao acaso e não significativas, começavam já a considerar apenas como momentânea a impossibilidade da síntese orgânica.

De facto, a síntese da ureia marcou uma data capital na História da Química, sistematicamente evidenciando as incapacidades explicativas das pretensões vitalistas. Contudo, alguns dos mais convictos, mantinham a ideia de que o cianeto de amónio, com o qual se sintetizara a ureia, podia encerrar forças anímicas que seriam incorporadas na nova ureia obtida. Finalmente, químicos como Kolbe e Berthelot sintetizariam compostos orgânicos directamente a partir dos elementos químicos, os mesmos que também entravam nos compostos minerais, afastando, assim, a ideia de qualquer força anímica que separasse a Química Orgânica da Química Inorgânica.

Podemos dizer que a intensa actividade experimental que se desenvolvia nos mais diversos domínios deu um precioso contributo para ultrapassar as teorias vitalistas que começavam a causar mais entraves do que a proporcionar avanços, por esse preconceito da impossibilidade da síntese laboratorial de compostos orgânicos. Não é, efectivamente, desprezável o efeito retardador que estas ideias causaram na evolução da Química.

$\mathrm{Na}$ mesma caminhada ao longo do século XIX, logo no ano de 1801 , Proust enunciara a lei das proporções definidas, constatando que uma combinação química determinada teria sempre a mesma composição. Tal ideia foi rebatida por Bertholet para quem a composição quantitativa de uma combinação não era constante, mas antes dependente das quantidades de reagentes intervenientes na reacção, pelo que as substâncias não se combinariam numa proporção fixa (uma tal constatação advinha de erros e imprecisões experimentais). Com o afã experimental de Berzelius, a proposta de Proust viria a triunfar.

Em muitas situações experimentais constatava-se, afinal, que, com frequência, dois elementos, ao combinarem-se, davam lugar a mais que um composto. É Dalton quem analisa ponderadamente estes processos e enuncia, em 1804, a lei das proporções múltiplas. Mas, se as leis ponderais haviam sido estabelecidas, não se tinha dado qualquer explicação satisfatória sobre "a que é que elas se deviam" e é aqui que entra a imaginação de Dalton para integrar essas leis ponderais numa teoria que as explicasse. Este químico retomou a ideia de constituição atómica da matéria, naturalmente que, desde logo, com a diferença introduzida pelo intervalo temporal que a separava da filosofia grega. Na nova proposta teórica, tudo se podia explicar considerando que um determinado composto, sem qualquer distinção pela sua natureza, se formava, sempre, pela união do mesmo número de átomos de cada um dos elementos que o integravam. Como cada tipo de átomo tinha um peso constante, as relações em peso eram inevitáveis.

É a partir de 1850 que a hipótese atómica vai sendo progressivamente admitida e que adquire rapidamente um conteúdo preditivo em todos os domínios da Química, sem excepção. Digamos que a admissão e consolidação da teoria atómica representou, na Química, um segundo grande avanço, como que uma segunda revolução química [3]. É, afinal, no ambiente experimental da Química Orgânica que a nova teoria acaba por sair reforçada, ao mesmo tempo que renova também esse domínio.

Kékulé (1829-1896), por meados do século XIX, já não podia dispensar a interpretação atómica. Este químico teve o mérito de tornar precisas certas noções que se encontravam ainda muito vagas, voltando à organização da matéria e à organização dos átomos nas moléculas. Explicou a isomeria como reorganização dos átomos nas moléculas e retomou a noção de valência, de um novo ponto de vista. O carbono tetravalente (descoberto em 1858 por Kékulé e por Couper simultaneamente) conduz à riqueza dos compostos orgânicos. Sete anos depois, Kékulé imaginava a representação hexagonal do benzeno onde nem todas as valências do carbono estavam saturadas. Este ciclo fechado teve como consequência um número fantástico de derivados: a naftalina, sintetizada por Aronheim, o alfa-naftol descoberto por Fitting, o estudo da antracina, da antraquinona, da piridina e, em geral, de todos os alcalóides.

Foi Wurtz (1817-1884) quem se fez, em França, profundo defensor do atomismo. Dumas, Saint-Claire Deville e Berthelot combateram, abertamente, o colega químico. Este último, nome incontornável na epopeia da Química Orgânica realizava em 1851 a síntese do álcool metílico, primeira etapa de uma longa série de outras sínteses, das quais a do acetileno viria a ser a mais memorável. Pela primeira vez, carbono e hidrogénio, na presença um do outro, combinavam-se para dar origem ao acetileno. Estudou ainda a esterificação dos álcoois puros através dos ácidos, processo a que se deve o éter sulfúrico da desinfecção das feridas e das anestesias. O seu espírito recusava-se, ainda, contudo, a admitir a hipótese atómica em que já se baseavam todos os cálculos da indústria química.

Mas os vitalistas não conseguiam travar a carreira de Wurtz. Do laboratório de Liebig este passou para a Faculdade de Medicina de Paris e daí para a Sorbonne, em 1875. Além da obra teórica em que se bate pelo atomismo, enriqueceu a Química Orgânica com a síntese das aminas em 1849 e do glicol em 1856. A sua obra foi completada por Karl Friedel (1832-1899) que, ouvindo Pasteur que ensinava na universidade de Estrasburgo sobre os mistérios da cristalografia, se interessou pela Química com as suas pesquisas sobre as cetonas e os aldeídos. Um tal trabalho valeu-lhe a condecoração da Legião de Honra. Sucedeu a Wurtz na cátedra de Química Orgânica da Sorbonne. Em 1877 publicava um novo método geral de síntese dos hidrocarbonetos e das ce- 
tonas. Ao sintetizar a amilbenzina por meio de um original processo de catálise com o cloreto de alumínio, Friedel deu um impulso a toda a indústria química dos corantes e dos produtos farmacêuticos, ao mesmo tempo que beneficiava a indústria da petroquímica.

A nova teoria atómica da matéria abrira caminho à noção de peso atómico e sua determinação experimental, que seria base da classificação dos elementos, em meados do século, da realização de um enorme e variado trabalho experimental, do desenvolvimento dos diferentes ramos da Química e, afinal, do conhecimento da estrutura da matéria e da superação da distinção entre matéria viva e matéria mineral.

Reforçando o atomismo e baseandose no conceito de valência, a Química
Orgânica foi, com a Síntese, conduzida a um estado de desenvolvimento que atingiu um ponto sem retorno. $O$ século XIX foi, como não podíamos deixar de realçar, a era das grandes sínteses que alcançaram todo o seu esplendor no século XX com o desenvolvimento massivo da síntese de polímeros para novos materiais.

Os milagres dos químicos orgânicos foram as sínteses do plástico, dos silicones, das vitaminas, das hormonas, dos antibióticos... Mas, podemos considerar que no século XXI o paradigma mudou e, da síntese orgânica tradicional, que centrava o seu estudo mais na optimização dos rendimentos do que na economia atómica e minimização de resíduos, existe uma filosofia emergente de síntese limpa/verde e ambientalmente sustentável que recorre a processsos catalíticos mais selectivos e menos energéticos, solventes alternativos menos poluentes e, especialmente, já a reacções sem solvente $[4,5]$.

\section{REFERÊNCIAS}

[1] J. Rosmorduc, De Tales a Einstein. História da Física e da Química, Editorial Caminho, Lisboa, 1983.

[2] H.W., Salzberg, From Caveman to Chemist. Circumstances and Achievements, American Chemical Society, Washington, 1991.

[3] S. Esteban Santos, Introducción a la Historia de la Química. UNED, Madrid, 2001.

[4] G.W.V. Cave, C.L. Raston, J.L. Scott, Chem. Commun., (2001) 2159-2169.

[5] F.M. Silva, P.S.B. Lacerda, J. Jones Júnior, Quimica Nova 28 (2005)103-110.

\section{Actualidades Científicas}

\section{Promovendo o OxigénIO}

O oxigénio é considerado o patinho feio da ressonância magnética nuclear biomolecular. Apesar de ser um átomo chave na estrutura de proteínas e ácidos nucleicos, a análise de outros átomos importantes como carbono, hidrogénio, nitrogénio e fósforo é consideravelmente mais comum, já que os espectros ${ }^{17} \mathrm{O}-\mathrm{NMR}$ apresentam, tipicamente, resoluções reduzidas. No entanto, num esforço de promover o oxigénio ao seu merecido lugar, investigadores desenvolveram um método que possibilita um modo mais prático de obtenção de espectros ${ }^{17} \mathrm{O}-\mathrm{NMR}$ de biomoléculas, com resoluções muito superiores às conseguidas anteriormente. O post-doc Jianfeng Zhu e o espectroscopista NMR Gang Wu da Queen's University, em Kingston, Ontário, desenvolveram o procedimento referido (J. Am. Chem. Soc., DOI: 10.1021/ja1079207). Wu e colaboradores já tinham anteriormente reportado o uso de campos magnéticos ultra-fortes para a análise pioneira de complexos proteína-ligantes por espectroscopia ${ }^{17} \mathrm{O}-\mathrm{NMR}$ em fase sólida
(Angew. Chem. Int. Ed., DOI: 10.1002/ anie.201002041). Todavia, neste novo trabalho, foi desenvolvida uma técnica designada por transição central de quadrupolo NMR que permite a extensão da análise ${ }^{17} \mathrm{O}-\mathrm{NMR}$ de alta resolução a biomoléculas em solução aquosa.

Ambos os estudos possibilitam o alcance de níveis de resolução sem precedentes para ${ }^{17} \mathrm{O}-\mathrm{NMR}$, e o novo método faculta um aumento de três ordens de magnitude do limite de tamanhos das biomoléculas acessíveis a análise NMR, em relação aos trabalhos anteriores. Wu salienta que o mais importante é o recurso à análise em solução, porque possibilita o estudo das moléculas biológicas no seu meio natural, em alternativa a uma estrutura cristalina rígida. A execução de ${ }^{17} \mathrm{O}-\mathrm{NMR}$ revela-se problemático, porque o ${ }^{17} \mathrm{O}$ é um núcleo quadrupolar, que gera linhas espectrais NMR alargadas e de interpretação difícil. Zhu e Wu lidaram com esta questão através da aplicação de campos magnéticos especialmente intensos e do enfoque em apenas um tipo de transição energética NMR, designada por transição central. Estas estratégias, conjugadas com a tendência das biomoléculas de tamanho elevado se movimentarem lentamente em solução (o que tende a minimizar o alargamento do sinal), permitiram uma redução das larguras dos sinais, aumentando significativamente a resolução do espectro.

A transição central de quadrupolo NMR pode ser usada no estudo de efeitos de ligação em deslocamentos químicos de oxigénio, formação de intermediários de reacção contendo oxigénio, ligações de ligandos com oxigénio a biomoléculas (como a ligação de oxalato a ovotransferrina, que consiste no objecto de um novo estudo). Wu e seus colaboradores prevêem que a nova técnica seja aplicável a complexos proteicos até $500 \mathrm{KDa}$.

(Adaptado do artigo de 03/01/2011 de Stu Borman: Elevating Oxygen,

Chemical \& Engineering News, http://pubs. acs.org/cen/news/89/i01/8901 notw4.html)

Paulo Brito (paulo@ipb.pt) Instituto Politécnico de Bragança 


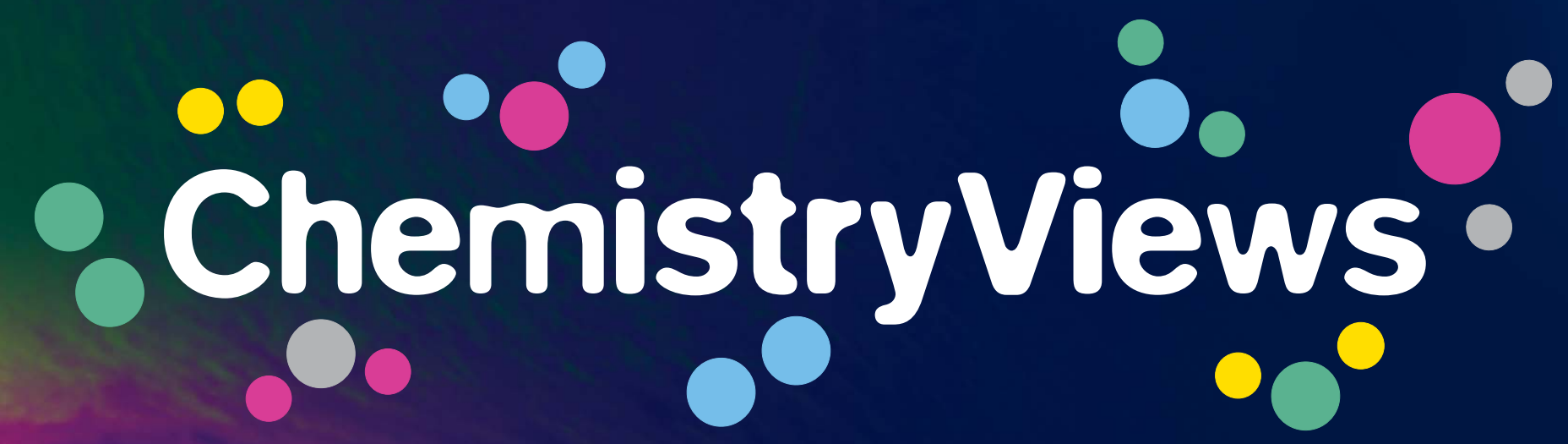

Presents top quality information from

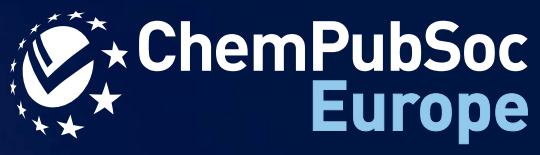

an organization of 14 chemical societies in continental Europe, publishing world leading journals like Chemistry - A European Journal

Gateway to WILEY's unique chemistry program including Angewandte Chemie, the flagship journal of

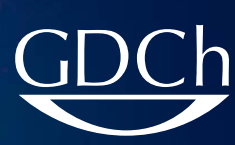

GeselLschaft Deutscher Chemiker

Free to view magazine

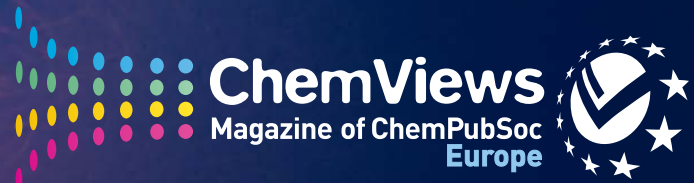

\section{Spot your favorite content at}

\section{www.ChemistryViews.org}

